\title{
Aethina tumida, an Exotic Parasite of Bees
}

Massimo Giangaspero* and Pasquale Turno

Department of Health Protection and Health Policy, Calabria Region, Italy

*Corresponding author: Massimo Giangaspero, Department of Health Protection and Health Policy, Calabria Region, Via Buccarelli 30, 88100, Catanzaro, Italy, Tel: 33-450-392875; E-mail: giangasp@gmail.com

Received date: September 01, 2015; Accepted date: September 07, 2015; Published date: September 14, 2015

Copyright: (c) 2015 Giangaspero M, et al. This is an open-access article distributed under the terms of the Creative Commons Attribution License, which permits unrestricted use, distribution, and reproduction in any medium, provided the original author and source are credited.

\begin{abstract}
The small hive beetle (Aethina tumida Murray), pest of honeybees, diffused from sub-saharan Africa in different countries, and has become a serious issue for beekeepers. Several methods have been developed to control this pest. Optimization of control measures, and possibly successful eradication measures against this invasive coleopteran will contribute to contain the general problem of the decline of $A$. mellifera worldwide.
\end{abstract}

Keywords: Aethina tumida; Control; Honeybee; Pest; Small hive beetle

\section{Editorial}

The small hive beetle (Aethina tumida Murray) (SHB), coleopteran of the family Nitidulidae, is a scavenger and parasite of colonies of honeybee (Figure 1) [1]. There are some reports of infestation of bumble bee species (Bombus terrestris and B. impatiens) [2]. A. tumida was previously known only from the sub-saharan regions of Africa. This exotic pest of bees showed the potential of a transboundary disease diffusing out from native areas, and has become a serious issue for beekeepers in different countries. Although it is considered to be a minor pest of bees in Africa, it is a major problem in areas where it has been introduced. In Africa, the native honeybees are able to control the infestation by eliminating the majority of beetle larvae. At the contrary, this behavior is not observed among european honeybees therefore infestation develops and constitutes threat for the colony. Bees seem to counter the action of the insect by imprisoning and blocking movements as first defense against beetle reproduction. However, this reaction is not sufficient to prevent predation. The bees even feed the beetle, responding to solicitations made by the parasite (one response every 12 solicitations). Highly likely to be transported internationally accidentally, due to the proved invasive character of the species outside its native range, with high reproductive potential and highly mobile locally, the risk of impact outcomes, predation, damages to apiaries and bees products, resulting in general negative impacts on agriculture and livelihoods, the small hive beetle infestation is on the list of diseases notifiable to the World Organisation for Animal Health (Office International des Épizooties: OIE) [1].

The adult beetles of Aethina tumida are dark brown to black and about one-half centimeter in length and $3 \mathrm{~mm}$ wide. The insects move quickly, prefer to escape from the light and seem insensible to cold $[3,4]$. The adult beetles are able to fly several kilometers (up to $13 \mathrm{~km}$ ) [2], aiding the rapid spread of infestation. The adults are attracted to bee colonies to reproduce. Female beetles lay irregular masses of eggs in cracks or crevices in a hive. The eggs hatch in 2-3 days into elongated, white-colored larvae with small spines in rows along the back [5]. Larvae will grow to $10-11 \mathrm{~mm}$ in length and require about
10-16 days maturing. Larvae that are ready to pupate leave the hive and burrow into soil near the hive to complete their cycle. Sandy and humid soil is most favorable [6]. The pupation period may last approximately 3-4 weeks. The pupae are whitish brown [3]. Newly emerged adults, red, but quickly becoming blackish, seek out hives and females generally mate and begin egg laying about a week after emergence. The adults may live up to 6 months. Hive beetles may have 4-5 generations per year under suitable conditions [3,7]. The small hive beetle can be a destructive pest of honeybee colonies, causing damage to comb, stored honey and pollen. Adult beetles and larvae feed on honey, pollen, honeybee eggs and larvae, dead adult bees, and combs. The beetles can also be a pest of stored combs, and honey (in the comb) awaiting extraction. The primary damage to colonies and stored honey caused by the small hive beetle is through the feeding activity of the larvae. While feeding, beetle larvae tunnel through wax comb with stored honey or pollen, damaging or destroying cappings and comb. Larvae defecate in honey and the honey becomes discolored from the feces. Activity of the larvae causes fermentation and frothiness in the honey, developing a characteristic odor of decaying oranges and, thereby rendering the honey foul, unpalatable to bees and considered unfit for human consumption. Hives and stored equipment with heavy infestations of beetles have been described as a mess. Various damages are caused by these beetles. Damage and fermentation cause honey to run out of combs, creating a mess in hives or extracting rooms. Its presence can also be a marker in the diagnosis of colony collapse disorder for honeybees. Heavy infestations may cause bees to abscond and desert their hives $[3,8]$.

In the African continent it has been reported in different countries, first in Zimbabwe in 1964 by Papadopoulo et al. [9], then in Uganda [10], Sudan [11], Kenya [12] and Nigeria [13]. The life cycle information is known primarily from studies in South Africa [14]. An alleged introduction in 2000 in Egypt was reported but not substantiated due to unreliable record [15]. From Africa, the pest has been further introduced to other continents. The United States first suffered from a wide diffusion of $A$. tumida out of native areas. Since its initial discovery in 1996 and its subsequent identification in 1998, from a commercial apiary in St. Lucie County, Florida, it was soon detected in indian river and 4 other counties, where it caused significant damage to honeybee colonies [16]. 


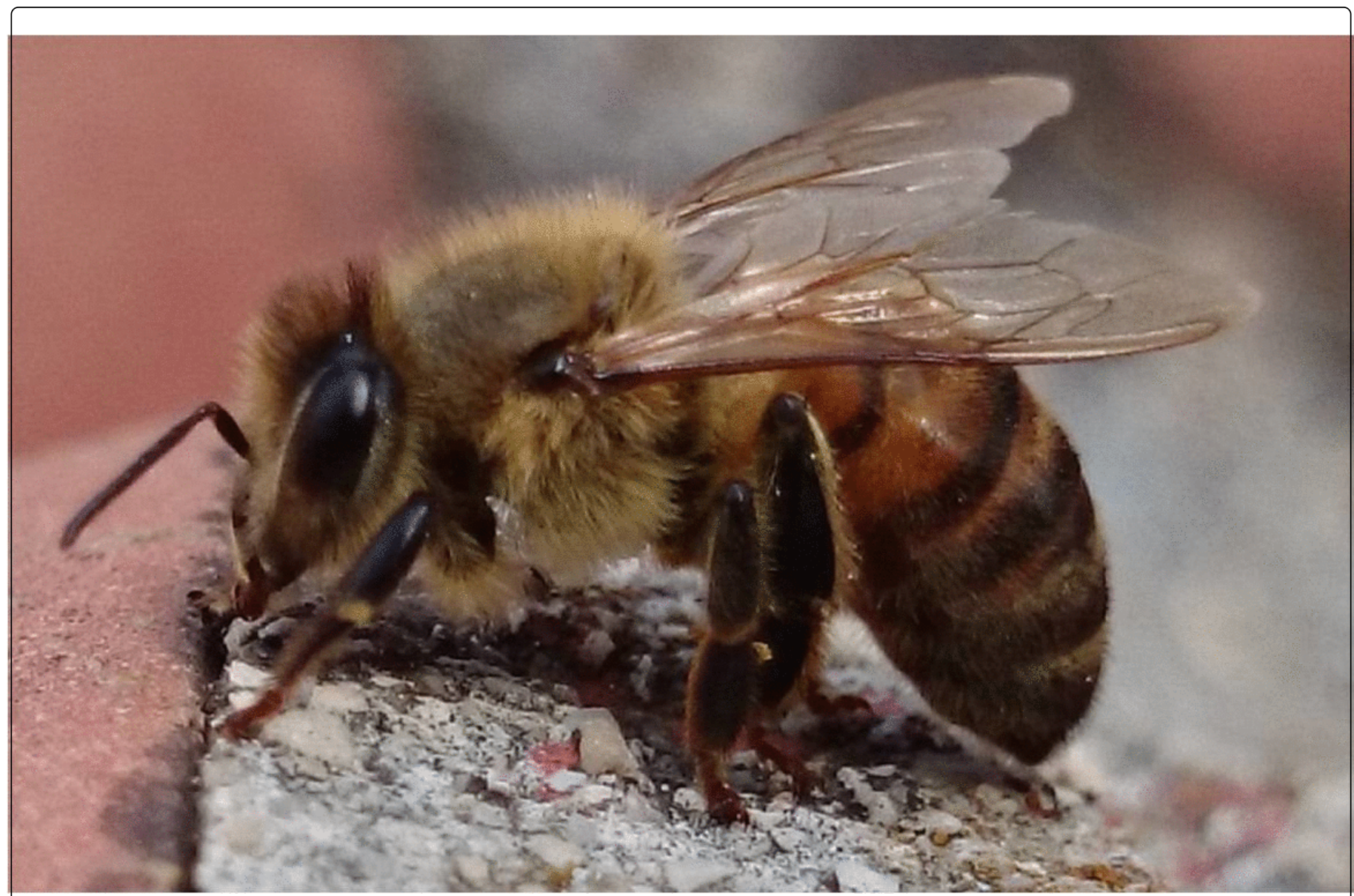

Figure 1: European Honeybee (Apis mellifera Linneaus) is natural host of the small hive beetle (Aethina tumida). The European honeybee is particularly susceptible to the infestation suffering from heavy losses. (Photo by Chiara Giangaspero).

Beetle specimens were found in beehives near Atlanta, Georgia [3] The intra-or interstate movement of honeybee colonies was prohibited until they could be inspected, to prevent further spread [16]. However, the species spread rapidly and is now very widespread throughout various other States in the USA, including North and South Carolina, California, Michigan, Pennsylvania, Ohio, Illinois, New Jersey, Minnesota, Maryland, Missouri, New York, Connecticut, Virginia, Texas, and also in Hawaii, where it was first recorded in 2010. In Canada, the small hive beetle has been detected in Manitoba (2002 and 2006), Alberta (2006), Québec (2008 and 2009), and Ontario (2010). In the Prairie Provinces (Manitoba and Alberta), measures were taken to control the pest and small hive beetles failed to establish a population. In Ontario, the introduction is restricted to a quarantine area in the southern part of the State. It is still to be determined whether the small hive beetle has been able to establish a resident population in Québec [17-19]. Furthermore, it has been also confirmed in Jamaica and Mexico in 2005 and 2007, respectively [15]. In Austral Asia, it was first found in Richmond, New South Wales and Queensland, Australia, in October 2002 [20], and is now considered endemic in those states, with some beetles recorded in Victoria and Western Australia [15,21]. Furthermore, a first SHB case was documented in the Philippines in June 2014. Inspection of apiaries in Lupon, Davao Oriental and General Santos in southern Mindanao Island in November 2014 revealed severe infestation, and majority of the bee colonies collapsed
[22]. In Europe, a first observation was made in Portugal in 2004. The beetle was intercepted at a border inspection post in a consignment of bees originated from Texas [23]. In this circumstance, the prompt seizure of contaminated bees and subsequent destruction prevented the introduction of the pest. In September 2014, the introduction and natural reproduction was first recorded in Southern Italy. The presence was localized in the regions of Calabria and Sicily [24]. To December 2014, since the first detection, the parasite was found in 59 loci in Calabria (56 in the province of Reggio di Calabria and 3 in the neighboring province of Vibo Valentia) and in one migratory apiary in the province of Siracusa, in Sicily. Larvae of SHB have been detected in only 5 hives, out of a total of 60 infested hives, and in one case, nymphaes have been collected in the soil. All the hives confirmed positive to SHB have been destroyed. To July 2015, 782 apiaries have been examined within and out of the different established protection and surveillance zones in Calabria and 318 in Sicily. There has been no A. tumida outbreak observed since December 2014. The current distribution of the parasite is schematically presented in Figure 2.

The small hive beetle can spread in various ways including with honeybee colonies, honeybee queens, bee products, equipment and supplies and, very significantly, ripe fruit [25]. Sea ports are therefore a significant potential point of entry. The movement of migratory beekeepers from Florida may have transported the beetle to other 
Page 3 of 7

states [3]. Recent findings also indicate transport of the beetles in package bees, but also by pollen and wax. In Manitoba, Canada, the parasite was introduced through imported beeswax from USA [17]. In Australia, it is suspected that a combination of importing queens from other countries and beekeepers moving their hives has caused the spread [26]. The mode of arrival of SHB in Southern Italy is unknown. However, it is meaningful that the first occurrence has been reported near the international sea port of Gioia Tauro in sentinel hives placed by the Department of Agriculture of the Mediterranean University of Reggio Calabria for early detection of eventual introduction of exotic bee pests onto the national territory. Furthermore, risk of introduction in new apiaries seems to be apiary density, beetle population levels, and ongoing mass beetle reproduction. Apiaries in forested habitats showed higher infestation levels, which was thought to be due to the presence of wild/feral colonies [27].

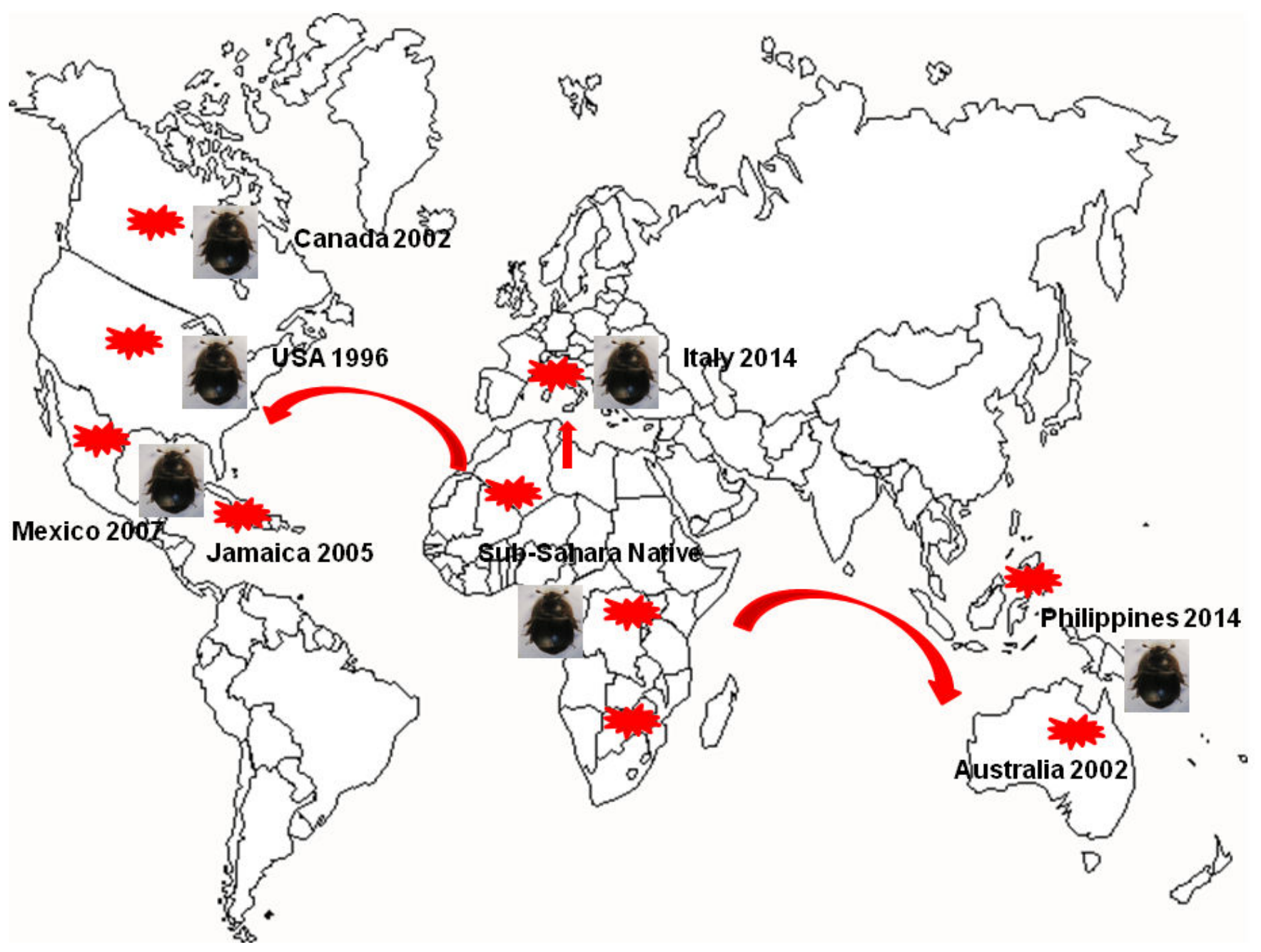

Figure 2: World distribution of the small hive beetle (Aethina tumida). The coleopteran, native from sub-saharan Africa spread in other continents. Year of first report is indicated.

Since this non-native species of beetle poses a major threat to the bee industry, this calls on the competent authorities to strengthen quarantine and other bio-security measures to prevent its spread. Policies on quarantine and bio-security measures should be streamlined in order to counteract the SHB threat. These should include movement control, prohibiting movement of bees from affected zones, controls at border inspection posts and field monitoring. SHB has been made notifiable within the european community in 2003 by Commission Decision 2003/881/EC [28]. In Canada and Australia beekeepers are to report immediately on learning of the occurrence of, or suspecting the existence of infestation by $A$. tumida $[29,30]$. However, despite in USA SHB is a serious widespread problem; $A$. tumida is monitored but not notifiable, as all other bee diseases [31]. Field monitoring to detect the presence of $A$. tumida can be supported by the installation of traps to capture adults in the hives [32]. However, traps are less efficient for the detection of adults than visual inspection of colonies, especially when the number of adults of $A$. tumida is very low. In Italy, during visits of five colonies resulted contaminated, adults have been collected in only two traps [24]. Therefore, it is important to inspect the entire hive to detect 
predators. Adults can be observed almost anywhere in a hive, although they are most often found on the rear portion of the bottom board of a hive. Each frame should be carefully and rapidly examined. Between the $20 \%$ to $50 \%$ of the colonies should be visited [24]. Subsequent identification of the collected insects by competent entomologists will avoid misdiagnosis with other resembling coleopteran as Meligethes aeneus, parasite of rapeseed, occasionally present in hives. The larvae of $A$. tumida may be confused with those of the wax worm (Galleria mellonella). A method to screen hive debris for the presence of SHB using real-time PCR in conjunction with an automated DNA extraction protocol is also available [33].

Several methods have been developed to control this pest. Chemical methods may be used in case of heavy infestation. Due to toxicity, risk of development of resistance, and potential residues in honey and in the environment, the use of insecticides to treat infestations should be carefully managed. Only authorized pharmacologically active substances, regularly registered as veterinary drugs should be used. Paradichlorobenzene (PDB) has been used for protecting empty stored combs. Coumaphos bee strips (Check-Mite+ ${ }^{\circ}$, Bayer Corporation), organophosphate pesticide, have been approved for use in hives for the control of small hive beetles in USA and Canada (registered against varroasis in Europe as Perizin ${ }^{\circ}$ ). Strips with $10 \%$ of Coumaphos are placed in the dark, under corrugated cardboard squares at the bottom of the hive, were adult beetles are more likely to seek refuge $[34,35]$. Other miticide molecules registered for varroasis as tau-fluvalinate or amitraze should be effective also against SHB. Taking into account that larvae burrow into soil between $1 \mathrm{~cm}$ and $20 \mathrm{~cm}$ of deep to pupate near the hive, a 40\% permethrin solution (Gard Star ${ }^{\circledR}, \mathrm{Y}$ Tex Corporation) may be shed onto the soil for the destruction of larvae and nymphs to stop the reproduction cycle [36]. Good results may be obtained also with combined utilization of strips with $10 \%$ of Coumaphos in the hives. Boiling water may be also used on the soil around the hives. However, this method is not totally efficient since despite the majority (83\%) of larvae remains at less than $30 \mathrm{~cm}$ of the hive, $17 \%$ at $90 \mathrm{~cm}$, and no one is generally observable at $1.80 \mathrm{~m}$ from hive [37], SHB can crawl large distances $(>100 \mathrm{~m})$ to find suitable conditions for pupation [21] and, they may proceed even up to five hundred meters before burrowing and complete their cycle [8].

A good management by beekeepers is necessary to protect against A. tumida. Maintenance of strong colonies and good husbandry are key elements [38]. The beetle is most often found in weak or failing hives and rarely affects strong hives, reproducing faster when the bee population is insufficient. Therefore, the most effective control against small hive beetle is maintaining colony strength, coupled with minimizing empty frames of comb. Healthy colonies, with young and vigorous queens, will be able to withstand the SHB invasion and to control their numbers in the hive. As the maintaining of colonies healthy is vital, it is even more important to treat for varroasis and ensure honeybees are as healthy as possible. However, some beekeepers have reported the rapid collapse of even strong colonies. As part of good management, manipulations should be reduced to essential necessary. It seems that adults of Aethina invade preferably hives after opening for routine works, in relation with an attraction provoked by odors from the hive [34,39]. In SHB, reactivity to odors emanated from the hive increases with the number and age of worker bees. Females are more reactive to odor stimulations, with a maximal response to honey under elaboration in comb cells. Thus, routine tasks carried out by apiarists can aid the spread of beetles and their establishment in the hive [3]. Furthermore, maintenance and hygiene of hives should not be neglected. During spring visit, all old wax, propolis and any other debris that may constitute an egg laying zone for SHB should be eliminated and burned. Wooden structures should be flame heated by blowtorch, and all parts and frames washed with diluted bleach [40].

Taking into account that bees show more precision in their flying and landing capacity than $A$. tumida, assays have been undertaken to modify access to hives in order to prevent the introduction of the beetles. In a preliminary study, the hive entrance was closed and replaced by a plastic tube of $19 \mathrm{~mm}$ diameter and about $10 \mathrm{~cm}$ long, located at $8-10 \mathrm{~cm}$ above the landing board [41]. The number of beetles has been significantly reduced in the hive, however the new opening system caused decrease of bee brood, increase of debris volume (more difficult to evacuate) and the quantity of water present in the hive due to bad ventilation. Such side effects have been partially attenuated by using bottom grids instead of conventional non ventilated plain wood bottoms and larger entrance [42]. A grid with 2 $\mathrm{mm}$ mesh impedes the passage of SHB adults [43]. Similar methods have been applied by Hood and Miller [44].

There are also several in hive mechanical traps currently available that can alert beekeepers to the presence of SHB and help to control its population, while also reducing the need for pesticides. The more effective ones are the Beetlejail Baitable, Hood Trap, the Freeman Beetle Trap, the West trap, the Australian, AJ's Beetle Eater and the Beetle Blaster $[45,46]$ All these traps have minimal impact upon normal honeybee activity. SHBs present in the hive will be attracted to the trap as a hiding place. Beer or cider vinegar can also be used as bite, as the beetle is attracted by plants and fermentation. Relatively simple and inexpensive, they use non-toxic food grade oil to suffocate the attracted beetles. But only $20 \%$ may be trapped, therefore further improvement of the traps is needed [8]. A trap must be installed in every colony in order to have an observable effect [47]. External traps to attract beetles out of the colonies (buckets containing a mixture of honey, pollen and larvae) are also proposed, but with scarce efficacy, since competing with other hives equally attractive [8].

Biological methods are also effective to counter the infestation by $A$. tumida. Pseudoscorpions (Ellingsenius fulleri and E. indicus) may protect bees from pests such as the small hive beetle [48]. While investigating the use of bottom boards to monitor hive beetles in bee colonies, Torto et al. [12] reported that the ant Pheidole megacephala was a key predator of larvae at a site in Kenya. Under laboratory conditions entomopathogenic nematodes including Steinernema riobrave and Heterorhabditis indica have shown excellent control potential against pupating larvae in the ground [49-51]. Soil nematodes specific to the SHB pose no threat to the environment and are exempt from registration and regulation. Beneficial nematodes are used by applying them to the soil while suspended in water. They may be applied as a pressurized spray or simply poured from a watering can. Nematodes applied to soil burrow downward in search of insect pests. Once found, nematodes enter the body of the insect and release symbiotic bacteria, Photorhabdus luminescens which quickly kills the pest. Released bacteria dissolve the internal tissues of the insect which becomes food for nematode growth and development. Matured nematodes then mate and lay eggs to produce more nematodes within the dead insect. Several such generations may occur over just a few days. After the inside of an insect is consumed, tiny infective stage nematodes leave the dead insect shell and begin searching for more pests. As many as 350,000 nematodes may emerge from a single dead insect after only 10 days-15 days. Numbers depend on insect size. Furthermore, taking into account that African bees appear to naturally resist to the diseases and pests as $A$. tumida or Varroa mites ( $V$. 
Page 5 of 7

destructor) that plague nearly all keepers of $A$. mellifera in other parts of the world, selection criteria may be also envisaged.

A more radical approach is represented by the application of eradication measures. The Italian authorities, the Directorate General for animal health and veterinary medicinal products, Ministry of Health, in agreement with the European Commission, developed sanitary measures in accordance with the european legislation, with the support of experts from the National Reference Center for Beekeeping of Experimental Zoo-prophylactic Institute (IZS) of Venezie, Padua, IZS of Mezzogiorno, the Veterinary Task force of the Region Calabria, and in collaboration with the European Union Reference Laboratory for Honey Bee Health, Sophia-Antipolis, France. Protection zones $(20 \mathrm{~km})$ and surveillance zones $(100 \mathrm{~km})$ have been instituted around infected sites, immediately after the official notification of the first outbreak. All the colonies confirmed contaminated have been destroyed by burning all the hives present in the site, followed by treatments with insecticides of residues and the soil. Teams composed by veterinarians, biologists and beekeeping experts have been deployed to undertake a surveillance program in the field. Monitoring of apiaries, through visual inspection and use of Shäfer type traps in the hives, and soil examination for the search of nymphs of $A$. tumida, have been organized in the protection and surveillance zones and, extended also out of the surveillance zone, on the base of risk assessment [24].

Attention should be paid to the behavioral differences between bees and beetles when burning contaminated colonies. In fact, smoke provokes in bees a well-known reflex pushing them blocked around the comb, avoiding any possible escape from burning hive, while the adults of $A$. tumida flies away at first signs of danger perceiving fire. Therefore, it is necessary to apply methods to prevent dispersion of SHB during operations to destroy hives. Another aspect to be considered is the extension of soil treatment to destroy pupae, taking into account the variability of distance from the hive where larvae migrate to find suitable conditions $[8,21]$. Furthermore, the adults are not only attracted to bee colonies to reproduce; they can survive and reproduce in other natural environments, feeding on other resources such as fruit, which makes the species very difficult to eradicate [2].

The choice of control methods or the combination of different strategies against $A$. tumida is certainly complex. The results obtained from different approaches followed to achieve the same goal are often difficult to compare, and stress the necessity to improve our understanding of this parasite. The application of control measures demonstrated that it is certainly possible to control its numbers and its impact. Nevertheless, there are opinions that suggest the impossibility to eradicate the new pest [40]. The beetle poses the greatest threat in warm humid climates, but it has also been found as far north as Canada. Much of Europe would therefore seem to offer a suitable habitat for the pest. There is a significant risk that the species could be introduced to other countries in Europe [15]. However, if the Italian authorities succeed to conduct successful eradication measures, this will represent a great result against this dangerous pest, preventing disastrous impact on the EU environment and economy.

Infestations of $A$. tumida can cause direct considerable financial loss to beekeepers [3]. Time and labour to detect and control the beetles and losses in terms of apiaries and honey production and other bee products, are the main economic losses suffered by the beekeeping industry [52]. Within two years of the discovery of $A$. tumida in the USA, at least 20,000 bee colonies had been destroyed by it, costing many millions of dollars. It has had a serious detrimental effect on the beekeeping industry in Australia as well [15]. The infestation by small hive beetles affects the conservation of indigenous bees causing a decline in native bees, such as $A$. mellifera, with negative impact on bee biodiversity [53]. Bee decline will have a significantly negative effect on pollination in habitats where plants rely on bees [54]. Honeybees provide a significant benefit to the environment, pollinating a wide variety of plants [55]. It is likely that honeybees provide over $50 \%$ of pollination of naturally occurring plants on which wild birds and mammals depend. Furthermore, infestation indirectly surely affect also food production since bees pollinate more that $30 \%$ of the global crop production [56]. In the United States is it estimated that bees pollinate up to $\$ 15$ billion worth of crops each year [56]. The value of pollination to the UK economy is estimated up to $£ 200$ million annually and honey production is worth an additional $£ 10$ million- $£ 30$ million [57].

A decline in bee numbers was observed worldwide. For example, in UK 100 years ago there were around 1 million bee hives; this had reduced to 400,000 in the 1950 s and further reduced to the 274,000 in 2008. The feral honeybee population is reported to have been largely wiped out by disease in the last 15 years [57]. In more than half of European countries-including the UK, France, Germany and Italy, there are not enough honeybees to properly pollinate the crops grown [58]. There may be a number of reasons that have been attributed to explain why honeybees are declining including loss of habitat, poor nutrition, and exposure to pesticides, various diseases and bee pests such as the introduced parasitic mite, Varroa destructor, considered to be the most devastating pest of $A$. mellifera worldwide. A. tumida comes to add to all other negative factors affecting honeybee health. In conclusion, optimization of control measures, and possibly successful eradication measures against $A$. tumida will contribute to contain the general problem of the decline of $A$. mellifera worldwide.

\section{References}

1. OIE (2013) Manual of diagnostic tests and vaccines for terrestrial animals. World Organisation for Animal, France.

2. OIE (2015) Terrestrial Animal Health Code. World Organisation for Animal Health, France.

3. Delaplane KS (1998) The small hive beetle, Aethina tumida. A new beekeeping pest. Bugwood publication 98: 11 .

4. Hood WM (2004) The small hive beetle, Aethina tumida: a review. Bee World 85: 51-59.

5. Cuthbertson AGS, Wakefield ME, Powell ME, Marris G, Anderson H, et al. (2013) The small hive beetle Aethina tumida: a review of its biology and control measures. Current Zoology 59: 644-653.

6. Ellis JD, Hepburn R, Luckman B, Elzen PJ (2004) Effects of Soil Type, Moisture, and Density on Pupation Success of Aethina tumida (Coleoptera : Nitidulidae). Environ Entomol 33: 794-798.

7. Cuthbertson AGS, Mathers JJ, Blackburn LF, Wakefield ME, Collins LE et al. (2008) Maintaining Aethina tumida (Coleoptera: Nitidulidae) under quarantine laboratory conditions in the UK and preliminary observations on its behaviour. Journal of Apicultural Research 47: 192-193.

8. Hood WM (2004) Les moyennes de lutte contre ce coléoptère. Proceedings of the XV National Congress of French beekeeping, Mende, France.

9. Papadopoulo P (1964) Enemies of bees. Rhodesia Agricultural Journal 61: 114-115.

10. Roberts E (1971) A survey of beekeeping in Uganda. Bee World 52: 57-67.

11. El-Niweiri MAA, El-Sarrag MS, Neumann P (2008) Filling the Sudan gap: the northernmost natural distribution limit of small hive beetles. Journal of Apicultural Research 47: 184-185. 
Page 6 of 7

12. Torto B, Fombong AT, Arbogast RT, Teal PEA (2010) Monitoring Aethina tumida (Coleoptera: Nitidulidae) with baited bottom board traps: occurrence and seasonal abundance in honey bee colonies in Kenya. Environmental Entomology 39: 1731-1736.

13. Akinwande KL, Badejo MA, Ogbogu SS (2013) Challenges associated with the honey bee (Apis mellifera adansonii) colonies establishment in south western Nigeria. AJFAND 13: 7467-7484.

14. Spiewok S, Pettis JS, Duncan M, Spooner-Hart R, Westervelt D, et al. (2007) Small hive beetle, Aethina tumida, populations I: Infestation levels of honeybee colonies, apiaries and regions. Apidologie 38: 595-605.

15. Food and Environment Research Agency (2010) The Small Hive Beetle: a serious threat to European apiculture. Sand Hutton, UK.

16. Thomas MC (1998) Florida pest alert-the small hive beetle. American Bee Journal 138: 565.

17. Kozak P (2010) Small Hive Beetle. Ontario Ministry of Agriculture, Food and Rural Affairs, Guelph, Ontario, Canada.

18. Kozak P (2012) Biosecurity practices for preventing the spread of Small Hive Beetle. Ontario Ministry of Agriculture, Food and Rural Affairs, Guelph, Ontario, Canada.

19. Ministry of Agriculture, Food and Rural Affairs, Canada (2013) Small Hive Beetle in Ontario.

20. Rhodes J, McCorkell B (2007) Small Hive Beetle Aethina tumida in New South Wales Apiaries 2002-2006. NSW Department of Primary Industries.

21. Annand N (2008) Small hive beetle management options. State of New South Wales, Department of Primary Industries, Australia. Primefact.

22. Brion ACB (2015) Small hive beetle poses threat to PHL bee industryexpert. Philippine News Agency, Philippines.

23. Murilhas AM (2005) Aethina tumida arrives in Portugal. Will it be eradicated? EurBee Newsletter 2: 7-9.

24. Mutinelli F, Montarsi F, Federico G, Granato A, Ponti MA, et al. (2014) Detection of Aethina tumida Murray (Coleoptera: Nitidulidae.) in Italy: outbreaks and early reaction measures. Journal of Apicultural Research 53: 569-575.

25. European Food Safety Agency (2013) Scientific opinion on the risk of entry of Aethina tumida and Tropilaelaps spp. in the EU. EFSA Journal 11: 3128 .

26. Neumann P, Elzen PJ (2004) The biology of the small hive beetle (Aethina tumida, Coleoptera: Nitidulidae): Gaps in our knowledge of an invasive species. Apidologie 35: 229-247.

27. Spiewok S, Duncan M, Spooner-Hart R, Pettis JS, Neumann P (2008) Small hive beetle, Aethina tumida, populations II: dispersal of small hive beetles. Apidologie 39: 683-693.

28. Commission of the European Communities (2003) Commission Decision of 11 December 2003 concerning the animal health and certification conditions for imports of bees (Apis mellifera and Bombus spp.) from certain third countries and repealing Decision 2000/462/EC.

29. Canadian Food Inspection Agency (2014) Immediately Notifiable Diseases. Guidance Document Repository, Canadian Food Inspection Agency, Canada.

30. Plant Health Australia (2013) Notifiable plant pests from Australian State and Territory legislation. State \& Territory Notifiable Pests 2013.

31. Animal and Plant Health Inspection Service (2014) U.S. National List of Reportable Animal Diseases. United States Department of Agriculture, USA.

32. Schaefer M0, Pettis JS, Ritter W, Neumann P (2008) A scientific note on quantitative diagnosis of small hive beetles, Aethina tumida, in the field. Apidologie 39: 564-565.

33. Ward L, Brown M, Neumann P, Wilkins S, Pettis J, et al. (2007) A DNA method for screening hive debris for the presence of small hive beetle (Aethina tumida). Apidologie 38: 272-280.

34. Elzen PJ, Baxter JR, Westervelt D, Randall C, Delaplane KS, et al. (1999) Field control and biology studies of a new pest species, Aethina tumida Murray (Coleoptera, Nitidulidae), attacking European honey bees in the Western Hemisphere. Apidologie 30: 361-366.
35. Neumann P, Hoffmann D (2008) Small hive beetle diagnosis and control in naturally infested honeybee colonies using bottom board traps and CheckMite+strips. Journal of Pest Science 81: 43-48.

36. Hood WM (2000) Overview of the small hive bettle Aethina tumida in North America. Bee World 81: 129-137.

37. Pettis JS, Shimanuki H (2000) Observations on the small hive beetle, Aethina tumida Murray, in the United States. American Bee J 140: 152-155.

38. Waite R, Brown M (2003) The small hive beetle. Bee craft 1: 4-5.

39. Suazo A, Torto B, Teal PEA, Tumlinson JH (2003) Response of the small hive beetle (Aethina tumida) to honey bee (Apis mellifera) and beehiveproduced volatiles. Apidologie 34: 525-533.

40. Menier JJ (2002) La lutte mécanique contre Aethina tumida, le Petit Coléoptère des Ruches, sera-t-elle plus efficace que la lutte chimique? La Santé de l'Abeille.

41. Ellis JD Jr, Delaplane KS, Hepburn R, Elzen PJ (2004) Controlling Small Hive Beetles (Aethina tumida Murray) in Honey Bee (Apis mellifera) Colonies Using a Modified Hive Entrance. American Bee Journal 142: 288-290.

42. Ellis JD, Delaplane KS, Hepburn R, Elzen PJ (2003) Efficacy of Modified Hive Entrances and a Bottom Screen Device for Controlling Aethina tumida (Coleoptera: Nitidulidae) Infestations in Apis mellifera (Hymenoptera : Apidae) Colonies. Journal of Economic Entomology 96: 1647-1652.

43. Ellis JD Jr, Delaplane KS, Hood WM (2002) Small Hive Beetle (Aethina tumida Murray) Weight, Gross Biometry, and Sex Proportion at Three Locations in the Southeastern United States. American Bee Journal 142: 520-522.

44. Hood WM, Miller G (2004) A Modified Constructed Honey Bee Hive with an Upper Entrance for the Control of Small Hive Beetles, Aethina tumida, Murray. Clemson University, USA.

45. Hood WM (2010) Integrated Pest Management. Dept. of Entomology, Soils, and Plant Sciences Clemson University, Clemson, South Carolina.

46. Zawislak J (2014) Managing Small Hive Beetles. University of Arkansas.

47. Peterson SM, Hood WM (2012) Investigations into "trapping sinks" to control small hive beetles, Aethina tumida, in apiaries of honey bees, Apis mellifera. Proceedings of the 25th American Bee Research Conference, Greenbelt, MD, USA.

48. Donovan BJ, Paul F (2005) Pseudoscorpions: the forgotten beneficials inside beehives and their potential for management for control of varroa and other arthropod pests. Bee World 86: 83-87.

49. Ellis JD, Spiewok S, Delaplane KS, Buchholz S, Neumann P, et al. (2010) Susceptibility of Aethina tumida (Coleoptera: Nitidulidae) larvae and pupae to entomopathogenic nematodes. J Econ Entomol 103: 1-9.

50. Cabanillas HE, Elzen PJ (2006) Infectivity of entomopathogenic nematodes (Steinernematidae and Heterorhabditidae) against the small hive beetle Aethina tumida (Coleoptera: Nitidulidae). Journal of Apicultural Research 45: 49-50.

51. Cuthbertson AGS, Mathers JJ, Blackburn LF, Powell ME, Marris G et al. (2012) Screening commercially available entomopathogenic biocontrol agents for the control of Aethina tumida (Coleoptera: Nitidulidae) in the UK. Insects 3: 719-726.

52. Calderón RA, Arce H, Ramírez JF (2006) The small hive beetle Aethina tumida Murray, an important problem affecting honey bees. Ciencias Veterinarias 24: 49-55.

53. Cuthbertson AGS, Brown MA (2009) Issues affecting British honey bee biodiversity and the need for conservation of this important ecological component. International Journal of Environmental Science and Technology 6: 695-699.

54. Delaplane KS, Mayer DF, Mayer DR (2000) Crop pollination by bees. CABI Publishing, Wallingford, UK.

55. Biesmeijer JC, Roberts SPM, Reemer M, Ohlemuller R, Edwards M et al. (2006) Parallel Declines in Pollinators and Insect-Pollinated Plants in Britain and the Netherlands. Science 313: 351-354. 
Citation: Giangaspero M, Turno P (2015) Aethina tumida, an Exotic Parasite of Bees. Clin Microbiol 4: e128. doi:10.4172/2327-5073.1000e128

Page 7 of 7

56. Mortensen AN, Schmehl DR, Ellis J (2013) Featured Creatures. Entomology \& Nematology.

57. Imperial College Consultants (2008) Honeybee health (risks) in England and Wales. Report to the National Audit Office. Imperial College Consultants, London, UK.
58. Castle P (2014) Europe is short of 13 million honeybee colonies for crop pollination. Food security news, University of Reading, UK. 